Secondly, we should consider whether we would be concentrating resources in the wrong area. From community studies of acute myocardial infarction, we know that mortality is highest soon after acute myocardial infarction and that despite a steady fall in hospital mortality, particularly in those patients enrolled in thrombolysis trials, the overall risk for an individual who has a heart attack has altered very little.$^{89} \mathrm{We}$ are therefore in danger of doing more and more in the way of treatment for fewer and fewer patients. Is this really the right way forward?

\section{CONCLUSIONS}

It has been suggested that primary PTCA is in danger of being "buried alive" ${ }^{10}$ An alternative view is that the pro-

1 Grech ED, Ramsdale DR. Angioplasty and acute myocardial infarction. Lancet 1994;342:191.

2 Grines CL, Browne KF, Marco J, et al. A comparison of immediate angioplasty with thrombolytic therapy for acute myocardial infarction. $N$ Engl fMed 1993.328:673-9.

3 Zijlstra F, de Boer MJ, Hoorntie JCA, Reiffers S, Reiber JHC, Suryapranata $H$. A comparison of immediate coronary angioplasty with intravenous streptokinase in acute myocardial infarction. $N$ Engl $₹$ Med intravenous strepto

4 Gibbons RJ, Holmes DR, Reeder GS, Bailey KR, Hopfenspirger MR, Gersh BJ. Immediate angioplasty compared with the administration of a thrombolytic agent followed by conservative treatment for acute myocardial infarction. N Engl f Med 1993;328:685-91.

5 A report of a working group of the British Cardiac Society: Cardiology in the cedure is in suspended animation and there it should remain until further large-scale trials guide us as to the best way forward, particularly in relation to patient selection. If primary PTCA is to be adopted into routine practice then it should be in the context of a strategy covering all opportunities for intervening from the moment symptoms begin. Such a strategy might reduce the high mortality in many patients with acute myocardial infarction more than the introduction of a single, expensive procedure for those that have already survived the period of highest risk.

R M BOYLE

Department of Cardiology, York District Hospital

district hospital. $\mathrm{Br}$ Heart $\mathcal{f}$ 1994;72:303-8.

6 Report of a working group of the British Cardiac Society: Coronary angioplasty in the United Kingdom. Br Heart f 1991;66:325-31.

7 Birkhead JS on behalf of the Joint Audit Committee of the British Cardiac Society and a Cardiology Committee of the Royal College of Physicians Society and a Cardiology Commitre

8 Fitzpatrick B, Watt GCM, Tunstall-Pedoe H. Potential impact of emergency intervention on sudden death from coronary heart disease in gency intervention on sudden death

9 Norris RM, Dixon GF, Chamberlain DA, Vincent R. Mortality from ischaemic heart disease (IHD) outside and inside hospital: the Brighton Heart Attack Study. Br Heart f 1994;71(suppl):33P.

10 Meier B. Balloon angioplasty for acute myocardial infarction: was it buried alive? Circulation 1990;82:2243-5.

\title{
Experience of primary angioplasty in the United Kingdom
}

\section{Spectre of an overwhelming increase in workload}

The benefits of reperfusion therapy for acute myocardial infarction are well established and most patients should now receive thrombolytic agents to achieve recanalisation of the occluded infarct-related vessel. ${ }^{1}$ However, thrombolytic therapy does have several limitations. Firstly, recanalisation is not achieved in at least $20 \%-30 \%$ of patients ${ }^{2}$ and only $50 \%$ will achieve TIMI grade 3 flow in the first 90 minutes. ${ }^{3}$ Secondly, of those patients in whom recanalisation occurs, $10 \%-30 \%$ will have early or late reocclusion (despite treatment with aspirin and heparin) leading to reinfarction, worsening left ventricular function, and death. ${ }^{45}$ Thirdly, intracranial bleeding can occur in $1 \%$ of patients, causing death in $35 \%-40 \% .^{6}$ In addition, $15 \%-20 \%$ of patients with myocardial infarction will have some contraindication to thrombolytic therapy. ${ }^{7}$

Though primary (or direct) percutaneous transluminal coronary angioplasty (PTCA) offers an opportunity to overcome most of these problems, major issues need to be addressed before this form of treatment can be applied nationwide.

Direct PTCA has been shown to have a high primary success rate (90\%-99\%) with few procedural complications and a low in-hospital mortality. ${ }^{89}$ It can establish TIMI grade 3 flow in up to $95 \%$ of patients within two hours of hospital admission ${ }^{10}$ and this has been our experience. Thrombolytic agents cannot achieve this. Primary angioplasty has a more rapid action and greater success because it can dislodge and mechanically disrupt thrombus as well as reduce any residual coronary stenosis caused by atheroma. These actions reduce the risks of recurrent ischaemia, reocclusion, and reinfarction. ${ }^{11}$ Primary PTCA also avoids the significant bleeding risks associated with systemically administered thrombolytics and reduces the formation of a haemorrhagic myocardial infarction. ${ }^{12}$ If necessary, residual intracoronary thrombus seen angiographically can be simultaneously, effectively, and more reliably treated with small doses of clot-specific thrombolytic drugs administered directly down the relevant vessel.

Primary PTCA leads to a reduction of infarct size and improved left ventricular function when compared with streptokinase therapy, with the most pronounced benefits being in those with anterior myocardial infarction presenting within two hours after the onset of symptoms. ${ }^{13}$ These impressive results are presumably the result of a rapid and effective restoration of blood flow to jeopardised myocardium. In addition to reducing the likelihood of recurrent myocardial ischaemia and reinfarction, immediate PTCA reduces the need for early additional revascularisation procedures and reduces in-hospital mortality, compared with intravenous thrombolytic therapy. Again these effects are a consequence of improved coronary blood flow and better left ventricular function. ${ }^{13}$ Brodie et al showed that after primary PTCA, patency of the infarct-related artery is the most important determinant of hospital survival and that left ventricular function measured after recovery is the most important determinant of late cardiac survival. ${ }^{14}$ The beneficial effects of primary PTCA were sustained (up to 36 months) after discharge ${ }^{1315}$ although as many as $28 \%$ of patients require a repeat PTCA for restenosis.

Primary PTCA can also be used successfully when thrombolytic therapy is contraindicated by a high risk of bleeding or an adverse haemodynamic state such as cardiogenic shock. ${ }^{1617-19}$ Indeed, it is probably the best treatment for achieving rapid reperfusion in such high risk subsets. ${ }^{19}$ 
Although the initial costs of primary PTCA are higher than thrombolytic therapy with streptokinase, use of anistreplase and r-tPA (alteplase), which are more expensive, will narrow the gap. Moreover, the in-hospital stay is shorter and readmission rates lower after PTCA than after thrombolytic therapy ${ }^{1320}$ and at one year the costs of primary PTCA were similar to streptokinase therapy and cheaper than treatment with r-tPA. ${ }^{13}$

Over and above these benefits, the necessary immediate coronary arteriography provides crucial information for treatment stratification. Those patients with left main coronary artery stenosis, severe three vessel coronary artery disease, or occluded vessels that are unsuitable for PTCA can be referred for coronary artery bypass surgery. Conversely, those with a patent or insignificant infarctrelated vessel may be selected for medical treatment rather than unnecessary thrombolytic therapy.

There are overwhelming advantages to primary PTCA in acute myocardial infarction but there are also drawbacks. Some of these are consequent to the nature of the procedure whereas others are major resource and manpower issues. Complications include those of cardiac catheterisation and PTCA. ${ }^{1321}$ Procedures can be simple and short ( $<20$ minutes) or complex and prolonged $(>2$ hours), even though it is usual to attempt only the infarctrelated vessel. Prolonged procedures, although infrequent, increase the exposure of the interventional cardiologist to radiation. Ventricular arrhythmia not uncommonly occurs shortly after coronary reperfusion but in the catheter laboratory this can be promptly treated by intravenous drug therapy or DC cardioversion. Right coronary artery procedures are more often troublesome than those in the left coronary artery and are more commonly associated with sinus arrest, atrioventricular block, idioventricular rhythm, and severe hypotension. ${ }^{22} 23$

\section{". . . it soon became obvious that resources were not.sufficient to offer a district service, let alone a regional one"}

Temporary pacing, inotropic support, and intra-aortic balloon pumping may be necessary. When much intracoronary clot is present, additional intracoronary thrombolytic therapy may be combined with PTCA; however, this increases the risk of femoral artery bleeding and haematoma formation. Primary coronary angioplasty, like elective PTCA, is associated with an operator-dependent morbidity and mortality that varies with the skill and experience of the interventional cardiologist. ${ }^{1321}$ It should only be considered in patients presenting early and when an experienced angioplasty team is available. Cardiac surgical back-up is essential if risks are to be minimised. ${ }^{10}$ Because facilities in the United Kingdom are limited, those interventional cardiologists who currently perform primary PTCA carefully select patients for this procedure rather than offer it to allcomers. Ideal patients might include those who are aged less than 60 years, who present within four hours of the onset of chest pain associated with acute ST segment elevation, and who have no previous acute infarction or a long history of angina. Patients with anterior infarction or contraindications to thrombolytic therapy may be particularly suitable. However, treatment of patients with previous myocardial infarction, a long history of angina, previous coronary artery bypass surgery, or proven multivessel or diffuse coronary disease is not contraindicated. Though such patients are technically unattractive prospects for primary PTCA they may benefit considerably from prompt reperfusion by this procedure.

In common with most other UK centres, most of our patients with acute myocardial infarction are treated with intravenous thrombolytic therapy. However, in recent years we have performed primary and rescue PTCA in over 100 patients. Patients underwent primary PTCA if they presented when a cardiologist was available and the cardiac catheter laboratory was unoccupied or about to become so. Thus most patients were treated in the evenings, early hours of the morning, and at the weekend. Initially we were motivated to continue this demanding activity because of our research interests and because we were impressed by the angiographic and clinical results achieved, but it soon became obvious that resources were not sufficient to offer a district service let alone a regional one. In the first 50 patients without cardiogenic shock that we treated by primary PTCA, the median time from onset of pain to presentation was 120 minutes (range 10-420 minutes) and the median time from presentation to recanalisation was 90 minutes (range 20-215 minutes). Recanalisation was usually achieved within minutes of the patient entering the catheter laboratory. Sixty two per cent of patients had multivessel disease and PTCA was performed to the right coronary artery in $40 \%$, left anterior descending in $44 \%$, left circumflex in $12 \%$, intermediate artery in $2 \%$, and saphenous vein graft in $2 \%$. In $96 \%$ of patients only the infarct-related artery was attempted. The remaining $4 \%$ had other critical stenoses or occluded vessels dilated. Intracoronary thrombus was seen in $68 \%$ of patients and adjunctive intracoronary thrombolytic therapy was used in $63 \%$ of these to help to disperse persistent thrombus. The primary success rate with PTCA was high: TIMI 3 flow was achieved in all patients. In two patients non-occlusive dissection developed in the right coronary artery (in one this may have been induced by the guide catheter). Most vessels (92\%) remained patent at 24 hours and in some left ventricular function showed a considerable visible improvement in those patients who had prompt reperfusion. Of the four reocclusions, three were promptly reopened by repeat PTCA and one in a distal right coronary artery was left alone. Complications included severe arrhythmias in 18 $(36 \%)$ and severe hypotension requiring fluids and inotropes in $10(20 \%)$; however, emergency coronary artery bypass grafting was not necessary and there were no deaths. Myocardial rupture and femoral artery complications did not occur although intravenous heparin was continued for up to 48 hours after PTCA. The high success rate and low major complication rate may be the result of our careful selection of what we thought to be "ideal relatively low-risk" cases, yet over $60 \%$ of these had multivessel disease at angiography.

If the mortality associated with myocardial infarction is confirmed to be significantly lower after PTCA than after conventional thrombolytic therapy (as a pooled analysis of the three major prospective clinical trials indicates $^{1324-26}$ ), the Department of Health should allocate appropriate funding for such a nationwide programme as part of their contribution to reducing the morbidity and mortality from heart disease. On a regional scale in the United Kingdom, this would also require a major com- 
mitment from trained interventionists and a significant change in working practices if consultants are to be available around the clock. It would also require additional catheter laboratory nursing staff, physiological measurement technicians, and radiographers as well as junior medical staff. In the face of the planned reforms of junior doctors' hours these staffing arrangements are unlikely to be achieved. Additional catheter laboratories will be required in regional centres, to avoid unacceptable competition for laboratory space by patients requiring elective investigation and intervention. Similarly, an expansion of high-dependency or coronary care units and additional cardiac surgical facilities would be needed. Reorganisation of the transport of suitable patients to interventional centres would be required and would involve general practitioners and the ambulance and paramedical services. Such personnel and the general public would have to be further educated in the diagnosis of acute myocardial infarction and the rationale for rapid treatment by primary PTCA.

\section{“. . . this would also require ... a significant change in working practices if consultants are to be available round the clock"}

Although evidence is now accumulating that primary PTCA in experienced hands is the most effective treatment for acute myocardial infarction, ${ }^{24-26}$ many questions need to be answered. These will require carefully controlled clinical trials similar to those conducted on thrombolytic agents and $\beta$ blockers. Who should be offered primary PTCA? Should there be age or time limits? When and where should the procedures be performed? And who should perform them? Will other interventional devices, capable of aspirating or mechanically destroying thrombus and atheroma prove of value in this group of patients and will we be able to afford them? Does intra-aortic balloon pumping improve outcome and if so which subgroups benefit the most? For how long should patients be heparinised after the procedure? Should they be treated with warfarin as well as with aspirin on discharge and for how long? Once successfully treated, should those patients with severe disease in the non-infarct related vessels undergo elective surgery or PTCA, or should symptoms, exercise stress testing, or routine angiography be used to identify those at high risk during follow up?

A lack of enthusiasm for primary PTCA among cardiologists worldwide has been intensified by the spectre of an overwhelming increase in workload (often during extremely unsocial hours) without the prospect of appropriate remuneration or additional staff to cope with the potentially uncontrollable demand. Both in Europe and the USA there has been little effort to perform clinical trials to answer many of the important questions raised. There have been no trials in the United Kingdom, despite published evidence that suggests that primary PTCA is better than thrombolytic agents. These studies are urgently needed. A working party should be set up in the United Kingdom to address the medical, social, and financial implications of a nationwide service for primary PTCA. Otherwise this effective treatment will continue to be offered only to select groups of patients by a few enthusiastic interventional cardiologists.

DAVID R RAMSDALE EVER D GRECH

Cardiothoracic Centre, Liverpool L14 3PE

1 ISIS-2. Randomised trial of intravenous streptokinase, oral aspirin, both or neither among 17,187 cases of suspected acute myocardial infarction: ISIS-2. Lancet 1988;ii:349-60.

2 Granger CB, Califf RM, Topol EJ. Thrombolytic therapy for acute myocardial infarction. A review. Drugs 1992;44:293-325.

3 The GUSTO Angiographic Investigators. The effects of tissue plasminogen activator, streptokinase, or both on coronary artery patency, ventricgen activator, streptokinase, or both on coronary artery patency, ventric-
ular function, and survival, after acute myocardial infarction. $N$ Engl f Med 1993;329:1615-22.

4 Ohman EM, Califf RM, Topol EJ, et al and the TAMI study group. Consequences of reocclusion after successful reperfusion therapy in acute myocardial infarction. Circulation 1990;82:781-91.

5 White HD, Cross DB, Elliott JM, Norris RM, Yee TW. Long-term prognostic importance of patency of the infarct-related coronary artery after thrombolytic therapy for acute myocardial infarction. Circulation 1994; 89:61-7.

6 de Jaegere PP, Arnold AA, Balk AH, Simoons ML. Intracranial hemorrhage in association with thrombolytic therapy: incidence and clinical predictive factors. $\mathcal{F} \mathrm{Am}$ Coll Cardiol 1992;19:289-94.

7 Cragg DR, Friedman HZ, Bonema JD, et al. Outcome of patients with acute myocardial infarction who are ineligible for thrombolytic therapy. Ann Intern Med 1991;115:173-7.

8 Stone GW, Rutherford BD, McConahay DR, et al. Direct coronary angioplasty in acute myocardial infarction: outcome in patients with single plasty in acute myocardial infarction: outcome

9 Kahn JK, Rutherford BD, McConahay DR, et al. Results of primary angioplasty for acute myocardial infarction in patients with multivessel coronary artery disease. $₹$ Am Coll Cardiol 1990;16:1089-96.

10 O'Neill WW, Brodie BR, Ivanhoe R, et al. Primary coronary angioplasty for acute myocardial infarction (the Primary Angioplasty Registry). Am $\mathcal{F}$ Cardiol 1994;73:627-34

11 Veen G, Meyer A, Verheugt FWA, et al. Culprit lesion morphology and stenosis severity in the prediction of reocclusion after coronary thrombolysis: angiographic results of the APRICOT study. $\mathcal{F} \mathrm{Am}$ Coll Cardiol 1993;22:1755-62

12 Mathey DG, Schofer J, Kuck KH, Beil U, Klöppel G. Transmural haemorrhagic myocardial infarction after intracoronary streptokinase. Clinical, angiographic, and necropsy findings. Br Heart $\mathcal{f} 1982 ; 48$ 546-51.

13 de Boer MJ. Primary coronary angioplasty in acute myocardial infarction. Rotterdam: Erasmus University, 1994. Thesis.

14 Brodie BR, Stuckey TD, Hansen CJ, et al. Importance of a patient infarctrelated artery for hospital and late survival after direct coronary angioplasty for acute myocardial infarction. Am 7 Cardiol 1992;69:1113-9.

15 O'Murchu B, Gersh BJ, Reeder GS, Bailey KR, Holmes DR. Late outcome after percutaneous transluminal coronary angioplasty during acute myocardial infarction. Am $₹$ Cardiol 1993;72:634-9.

16 O'Keefe JH, Rutherford BD, McConahay DR, et al. Early and late results of coronary angioplasty without antecedent thrombolytic therapy for acute myocardial infarction. Am $\mathcal{F}$ Cardiol 1989;64:1221-30.

17 Brodie BR, Weintraub RA, Stuckey TD, et al. Outcomes of direct coronary angioplasty for acute myocardial infarction in candidates and noncandidates for thrombolytic therapy. Am $\mathcal{F}$ Cardiol 1991;67:7-12.

18 Himbert D, Juliard JM, Steg PG, et al. Primary coronary angioplasty for acute myocardial infarction with contraindication to thrombolysis. Am $\mathcal{F}$ Cardiol 1993;71:377-81.

19 Lee L, Erbel R, Brown TM, et al. Multicenter Registry of angioplasty therapy of cardiogenic shock: initial and long term survival. $\mathcal{f} \mathrm{Am}$ Coll Cardiol 1991;17:599-60.

20 Stone GW, Grines CL, Browne KF, et al. Primary angioplasty reduces recurrent ischemic events compared to tPA in myocardial infarction: implications for early discharge. Circulation 1993;88:I-105A.

$21 \mathrm{Kahn} \mathrm{JK,} \mathrm{Rutherford} \mathrm{BD,} \mathrm{McConahay} \mathrm{DR,} \mathrm{et} \mathrm{al.} \mathrm{Catheterization} \mathrm{laboratory}$ events and hospital outcome with direct angioplasty for acute myocardial events and hospital outcome with direct
infarction. Circulation 1990;82:1910-5.

22 Gacioch GM, Topol EJ. Sudden paradoxic clinical deterioration during angioplasty of the occluded coronary artery in acute myocardial infarcangioplasty of the occluded coronary arter
tion. $₹ \mathrm{Am}$ Coll Cardiol 1989;14:1202-9.

23 Grech ED, Ramsdale DR. Termination of reperfusion arrhythmia by coronary artery occlusion. Br Heart $\mathcal{f} 1994 ; 72: 94-5$.

24 Grines CL, Browne KF, Marco J, et al for the primary angioplasty in myocardial infarction study group. A comparison of immediate angioplasty with thrombolytic therapy for acute myocardial infarction. $N$ Engl f Med 1993;328:673-9.

25 Zijlstra F, de Boer MJ, Hoorntje JCA, Reiffers S, Reiber JHC, Suryapranata HA. A comparison of immediate coronary angioplasty with intravenous streptokinase in acute myocardial infarction. $N$ Engl $\mathcal{F}$ Med 1993;328:680-4.

26 Gibbons RJ, Holmes DR, Reeder GS, Bayley KR, Hopfenspirger MR, Gersh BJ. Immediate angioplasty compared with the administration of a thrombolytic agent followed by conservative treatment for myocardial infarction. N Engl f Med 1993;328:685-91. 